\title{
Impact of COVID-19 on the Practice of Otorhinolaryngology in Nigeria
}

\author{
Nurudeen Adebola Shofoluwe ${ }^{1}$, Jamila Lawal ${ }^{2}$, Abdullahi Musa Kirfi ${ }^{3}$, \\ Mohammed Bello Fufore ${ }^{4}$, Olushola Abdulrahman Afolabi ${ }^{5}$
}

${ }^{1}$ Department of Otorhinolaryngology, Ahmadu Bello University \& Ahmadu Bello University Teaching Hospital, Zaria, Nigeria ${ }^{2}$ Division of Otorhinolaryngology, Department of Surgery, Kaduna State University and Barau Dikko Teaching Hospital, Kaduna, Nigeria

${ }^{3}$ Department of Otorhinolaryngology, Abubakar Tafawa Balewa University Teaching Hospital, Bauchi, Nigeria

${ }^{4}$ Department of Otorhinolaryngology, Federal Medical Centre, Yola, Nigeria

${ }^{5}$ Department of Otorhinolaryngology, University of Ilorin Teaching Hospital, Ilorin, Nigeria

Email: *shofoisma@gmail.com

How to cite this paper: Shofoluwe, N.A., Lawal, J., Kirfi, A.M., Fufore, M.B. and Afolabi, O.A. (2021) Impact of COVID-19 on the Practice of Otorhinolaryngology in Nigeria. International Journal of Otolaryngology and Head \& Neck Surgery, 10, 300-312.

https://doi.org/10.4236/ijohns.2021.104027

Received: May 20, 2021

Accepted: July 9, 2021

Published: July 12, 2021

Copyright $\odot 2021$ by author(s) and Scientific Research Publishing Inc. This work is licensed under the Creative Commons Attribution International License (CC BY 4.0).

http://creativecommons.org/licenses/by/4.0/

(c) (i) Open Access

\begin{abstract}
Background: The 2019 novel corona virus disease (COVID-19) pandemic broke out in Wuhan, Hubei province in China in December 2019. Available research so far showed that Otolaryngologists had an elevated risk of exposure to SARS-CoV-2 due to the high viral load in the respiratory tract, which is the primary area of examination and instrumentation. We aimed to present our findings on the impact of this pandemic on Otolaryngology practice in Nigeria. Materials and Methods: This study was conducted online in September, 2020 amongst otolaryngologists in secondary and tertiary health centers across Nigeria using the survey monkey. Analysis was done using SPSS version 20. Results: A total of 102 ORL practitioners in Nigeria were assessed in this study. The mean age of the respondents was $42.4 \pm 7.9$ years; majority (54.9\%) were Consultants and their duration of ORL practice ranged between 1 - 37 years. All the respondents felt being an ENT Surgeon exposes them to higher risk of contracting COVID-19 in their practice while $93 \%$ of them felt unsafe to perform throat examination during COVID-19 pandemic. Similarly, $74.5 \%$ feel unsafe to perform rhinoscopy while $67.7 \%$ of the respondents feel unsafe to do anterior rhinoscopy, posterior rhinoscopy and rigid nasal endoscopy. Conclusion: Otolaryngologist is at high risk of being infected with SARS COV-2 as they cope with upper respiratory tract during diagnosis, clinical review, sampling and surgery. The pandemic has affected almost all aspects of Otolaryngologic practice in Nigeria.
\end{abstract}

\section{Keywords}

Impact, Nigeria, Otolaryngologic, Practice, SARS-CoV-2 


\section{Introduction}

The 2019 novel corona virus disease (COVID-19) pandemic broke out in December 2019 in the city of Wuhan, Hubei province in China [1]. This disease was subsequently named Coronavirus disease 2019 (COVID-19) by the World Health Organization (WHO) and has spread globally affecting over 168.5 million people and resulting in more than 3.3 million deaths as of May $12^{\text {th }}, 2021$ [2].

The aetiology was determined to be a novel Coronavirus (originally called 2019 novel Coronavirus or 2019-nCoV). It was found to be very closely related to Severe Acute Respiratory Syndrome (SARS) viruses and has been named SARS-CoV-2 [3].

The available evidence so far has suggested that Otolaryngologists are at increased risk of occupational SARS-CoV-2 exposure due to the high viral load in the upper respiratory tract which is the area of frequent examination and instrumentation in Otorhinolaryngology (ORL) practice [4]. Indeed, the first physician deaths during the COVID-19 and SARS outbreaks were Otolaryngologists [4].

The first case reported of physician fatality related to COVID-19 in Wuhan, China, was that of an Otolaryngology physician on January 25, 2020 [5]. It will be pertinent to know the level of our risk and exposure to this deadly pandemic in a low-resource setting like ours.

This study aimed to determine the level of exposure of Otolaryngologist to COVID infection and to determine the level of precautionary measures in place in our health care facilities to prevent or reduce the exposure of Ear Nose and Throat Specialist to the viral disease.

\section{Materials and Methods}

This was an online questionnaire based web study conducted among the Otolaryngology trainee and trainers in Nigeria in secondary and tertiary health centers in Nigeria using the survey monkey platform. A brief introduction on the aims and objectives of the study was stated, consent to participate in the study and confidentiality of respondents was assured. The web based online questionnaire was distributed through various platform or groups in different geopolitical zones in the country, subspecialty training platforms, regional groups and national groups. A Uniform Resource Locator (URL) generated from the survey monkey platform was copied and sent via email to the survey population and also through social media platform such as WhatsApp groups of Otorhinolaryngologist in Nigeria.

Ethical clearance was obtained from the ethical review committee of the $\mathrm{Na}$ tional Ear Care Centre Kaduna, Nigeria. The duration of the online study was three (3) weeks in September 2020, and the data obtained was analyzed using the Statistical Product and Service Solutions (SPSS), 20.

\section{Result}

A total of 102 ORL practitioners in Nigeria were assessed in this study. The age 
range of the respondents was 29 - 60 years with the mean age of $42.4 \pm 7.9$ years. Majority of the participants $74(72.5 \%)$ were within the age range of $29-48$ years. There were $87(85.3 \%)$ males and $15(14.7 \%)$ females with a male to female ration of 5.8:1 (Table 1 ).

Table 1. Socio demographic profile of respondents.

\begin{tabular}{|c|c|c|}
\hline Age group & Frequency & Percent \\
\hline 29 - 38 years & 40 & 39.2 \\
\hline $39-48$ years & 34 & 33.3 \\
\hline $49-58$ years & 27 & 26.5 \\
\hline 59 years and above & 1 & 1.0 \\
\hline Total & 102 & 100 \\
\hline \multicolumn{3}{|l|}{ Gender } \\
\hline Male & 87 & 85.3 \\
\hline Female & 15 & 14.7 \\
\hline Total & 102 & 100 \\
\hline \multicolumn{3}{|c|}{ Professional Rank of Respondents } \\
\hline Consultants & 56 & $54.9 \%$ \\
\hline Senior Registrar & 23 & $23.5 \%$ \\
\hline Registrar & 21 & $21.6 \%$ \\
\hline \multicolumn{3}{|c|}{ Sub Specialty of Respondents } \\
\hline General ENT & 69 & $67.7 \%$ \\
\hline Head and Neck & 15 & $14.7 \%$ \\
\hline Rhinology & 8 & $7.8 \%$ \\
\hline Pediatric ENT & 6 & $5.9 \%$ \\
\hline Otology & 4 & $3.9 \%$ \\
\hline Total & 102 & 100 \\
\hline \multicolumn{3}{|l|}{ Duration of ORL Practice } \\
\hline $1-10$ years & 56 & $54.9 \%$ \\
\hline $11-20$ years & 35 & $34.3 \%$ \\
\hline 21 - 30 years & 8 & $7.9 \%$ \\
\hline 31 - 40 years & 3 & $2.9 \%$ \\
\hline Total & 102 & 100 \\
\hline \multicolumn{3}{|c|}{ Geo-Political Distribution of Respondents } \\
\hline North West & 34 & $33.3 \%$ \\
\hline North Central & 22 & $21.6 \%$ \\
\hline South West & 20 & $19.6 \%$ \\
\hline North East & 11 & $10.8 \%$ \\
\hline South East & 9 & $8.8 \%$ \\
\hline South South & 6 & $5.9 \%$ \\
\hline Total & 102 & 100 \\
\hline
\end{tabular}


Most of the respondents, 56 (54.9\%) were Consultants while 24 (23.5\%) and $22(21.6 \%)$ were senior registrars and registrars respectively. The duration of ORL practice of respondents ranged from $1-37$ years with the mean duration of ORL practice of $10.6 \pm 8.1$ years of ORL practice. Duration of ORL practice (in years) among respondents with majority $56(54.9 \%)$ being within $1-10$ years of ORL practice (Table 1).

The geographical distribution of respondents with majority 34 (33.3\%) of the respondents being from the north-west geo-political zone and the least from the south-south geo-political zone, $6(5.9 \%)$ as seen in (Table 1$)$.

Majority, 69 (67.7\%) of the respondents practiced General ENT and only 4 (3.9\%) of the respondents were Otologists (Table 1).

Forty-Six (45.1\%) of the respondents had interacted with a suspected case(s) of COVID-19 patient(s) in their clinics. Thirty (29.4\%) of the respondents have at one time or the other identified and isolated a patient(s) with corona virus related symptoms as precautionary measure. Almost half, 50 (49.0\%) of the respondents were said to have had full PPEs for use in their facilities when confronted with a suspected case of COVID-19 (Table 2).

For those who don't have full PPEs in their centres, 75 (73.5\%) used surgical face mask, 63 (61.8\%) used N95 face mask, 62 (60.8\%) used eye protective goggles/face shield, 43 (42.2\%) used head cover, 33 (32.4\%) used combine surgical gown with plastic apron, 15 (14.7\%) used others while only two $(2.0 \%)$ used powered air-purifying respirator (Table 2).

Based on clinical practice and exposure to COVID-19, all the respondents (100\%) think being an ENT Surgeon exposes them at higher risk of contracting COVID-19 infection in their clinical practice and $83(81.4 \%)$ of the respondents intend to screen their patients for COVID-19 before taking them for surgery (Table 3).

Most Otolaryngologists (70.6\%) discontinued elective operations, whereas the majority of clinic endoscopic procedures (55.4 percent), routine clinical procedures ( 82.3 percent), and ward admission ( 86.3 percent) were drastically reduced (Table 4).

Table 2. Infection control questions during COVID-19 pandemic.

\begin{tabular}{lccc}
\hline \multicolumn{1}{c}{ Infection Control of COVID-19 Questions } & Yes (\%) & No (\%) & Total (\%) \\
\hline $\begin{array}{l}\text { Have you ever interacted with a suspected case of COVID -19 } \\
\text { patient in the clinic? }\end{array}$ & $46(45.1)$ & $56(54.9)$ & $102(100)$ \\
$\begin{array}{l}\text { Have you ever identified \& isolated a patient with COVID-19 } \\
\text { related symptoms in the clinic as precautionary measure? }\end{array}$ & $30(29.4)$ & $72(70.6)$ & $102(100)$ \\
$\begin{array}{l}\text { Do you have facilities in the clinic for hand washing or hand } \\
\text { sanitizers for patients before entering the consulting room? }\end{array}$ & $93(91.2)$ & $9(8.8)$ & $102(100)$ \\
$\begin{array}{l}\text { Do you have facilities for molecular testing to screen or diagnose } \\
\text { patient(s) with COVID-19 related symptoms in your facility? }\end{array}$ & $37(36.3)$ & $65(63.7)$ & $102(100)$ \\
$\begin{array}{l}\text { Do you have full Personal Protective Equipment for use in your } \\
\text { facility when confronted with a suspected case of COVID-19? }\end{array}$ & $50(49.0)$ & $52(51.0)$ & $102(100)$
\end{tabular}


Table 3. Clinical practice questions and measures taken during COVID-19 pandemic.

\begin{tabular}{|c|c|c|c|}
\hline Clinical Practice Questions & Yes $(\%)$ & No $(\%)$ & Total (\%) \\
\hline $\begin{array}{l}\text { Do you think being an ENT Surgeon you are at higher risk of } \\
\text { COVID - } 19 \text { infection in your clinical practice? }\end{array}$ & $102(100)$ & $0(0.0)$ & $102(100)$ \\
\hline Do you use telemedicine since onset of COVID-19 pandemic? & $62(60.8)$ & $40(39.2)$ & $102(100)$ \\
\hline $\begin{array}{l}\text { Do you think the 'in person consultation' has decreased and } \\
\text { patients now prefer telephone consultation, text message or } \\
\text { telemedicine? }\end{array}$ & $57(55.9)$ & $45(44.1)$ & $102(100)$ \\
\hline $\begin{array}{l}\text { Will you subsequently intend to screen your patients for } \\
\text { COVID-19 before consultation? }\end{array}$ & $52(51.0)$ & $50(49.0)$ & $102(100)$ \\
\hline $\begin{array}{l}\text { Do you intend to screen your patient for COVID-19 before } \\
\text { surgery? }\end{array}$ & $83(81.4)$ & $19(18.6)$ & $102(100)$ \\
\hline $\begin{array}{l}\text { Post-COVID-19 will you still see all patients as the Pre-COVID } \\
\text { era? }\end{array}$ & $44(43.1)$ & $58(56.9)$ & $102(100)$ \\
\hline
\end{tabular}

Table 4. State of routine clinic and theatre activities during COVID-19 pandemic.

\begin{tabular}{cccccc}
\hline Routine Procedures & Halted & Decreased & Static & Increased & Total \\
\hline Clinic endoscopic procedure & $43(42.6 \%)$ & $56(55.4 \%)$ & $1(1.0 \%)$ & $1(1.0 \%)$ & $101(100 \%)$ \\
Routine clinic procedure & $11(10.8 \%)$ & $84(82.3 \%)$ & $6(5.9 \%)$ & $1(1.0 \%)$ & $102(100 \%)$ \\
Ward admission & $11(10.8 \%)$ & $88(86.3 \%)$ & $3(2.9 \%)$ & $0(0.0 \%)$ & $102(100 \%)$ \\
Elective operation & $72(70.6 \%)$ & $28(27.4 \%)$ & $2(2.0 \%)$ & $0(0.0 \%)$ & $102(100 \%)$ \\
Emergency operation & $1(1.0 \%)$ & $62(60.8 \%)$ & $34(33.3 \%)$ & $5(4.9 \%)$ & $102(100 \%)$ \\
\hline
\end{tabular}

Ninety percent of the respondents said that a patient presenting with anosmia raises their suspicion of COVID-19. Similarly, $87.3 \%, 70.6 \%, 69.6 \%$ and $64.7 \%$ of the respondents said patients presenting with sore throat, dry cough, difficulty with breathing, hyposmia or anosmia and fever respectively raises their suspicion of corona virus. Again, $48.4 \%$ and $48.0 \%$ of the respondents said rhinorrhea and sneezing respectively are common ENT symptoms of COVID-19.

Ninety three percent of the respondents said they feel unsafe to perform throat examination during COVID-19 pandemic while $91.2 \%$ and $85.3 \%$ of the respondents feel unsafe to perform tracheostomy and flexible/rigid nasopharyngoscopy respectively during COVID-19 pandemic. Similarly, $74.5 \%$ feel unsafe to perform posterior rhinoscopy, $68.6 \%$ feel uncomfortable to do anterior rhinoscopy while $67.7 \%$ of the respondents feel unsafe to do nasal packing/removal or manipulation.

With regards to measures being used for self-protection against COVID-19, 52 (51.0\%) of the respondents used face mask, 21 (20.6\%) maintained safe distance, $11(10.8 \%)$ used protective screens, 7 (6.9\%) used hydroxy alcoholic solutions, 3 (2.9\%) used goggles and 8 (7.8\%) used other protective means. Again, with regards to type of mask used during consultation for self-protection against COVID 19, 61 (59.8\%) of the respondents used surgical mask/ffp1, another 61 (59.8\%) used ffp2 (N95) mask, 10 (9.8\%) used ffp3 (N99) mask and 5 (4.9\%) 
used home-made (cloth) masks. Measures being taken at the clinics in other to prevent spread of COVID-19 are illustrated with a Pie Chart (Figure 1).

With regards to planning for patients' consultation post COVID-19 pandemic, $62(60.8 \%)$ of the respondents think they can consult all patients without selection, 24 (23.5\%) think they can only consult selected patients at risk of complications if not treated, $14(13.7 \%)$ are planning to see only selected patients who might require surgery while others accounted for $2(2.0 \%)$. On the category of patients to be screen for COVID-19, 64 (62.7\%) of the respondents are of the opinion that screening for COVID-19 should be done for all patients, $20(19.6 \%)$ believed that the screening should be limited to only those going for surgery, while $18(17.7 \%)$ are of the opinion that only patients for endoscopy should be screened for SARS-CoV-2 virus. Seventy three (71.6\%) of the respondents agreed that polymerase chain reaction (PCR) is the preoperative investigation of choice for screening for corona virus (Figure 2).

With regards to academic and training research activities, 97 (95.1\%) of the respondents said that the frequency of academic training and research activities have changed since the advent of corona virus. Table 5 gives detail of the changes in academic training and research activities during COVID-19 pandemic while the use of telemedicine, which is the use of telecommunications and technology in academic training and learning have increased significantly since advent of COVID-19 to as high as $76.5 \%$ (Figure 3).

Fifty-nine (57.8\%) of the respondents continued with their academic and research activities despite the COVID-19 pandemic (mostly using virtual means). Details of method used for the academic training or meetings during COVID-19 pandemic (Figure 4).

\section{Discussion}

Otolaryngologist may not seem to be in the frontline with COVID-19 but we do have a key role to play, and this must be planned. All the data from China, Iran, Italy suggests that ENT surgeons are an extremely high-risk group therefore we

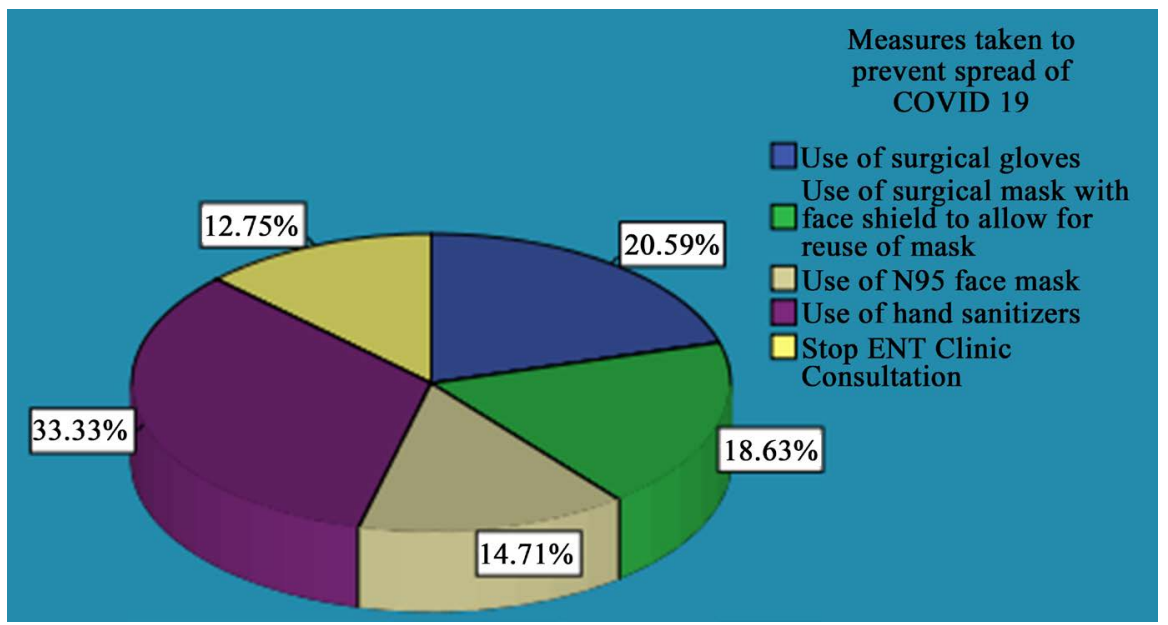

Figure 1. Measures taken to prevent spread of COVID-19. 


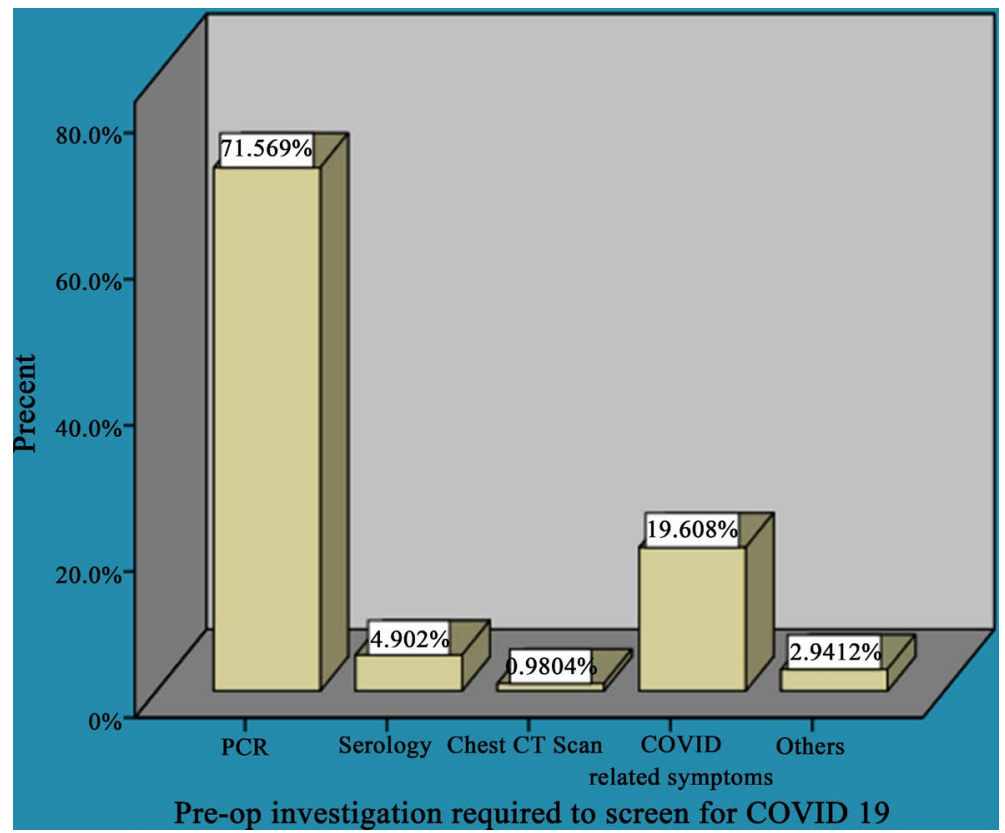

Figure 2. Responses of respondents on the preoperative investigation required to screen for COVID-19.

Table 5. Academic training and research activities during COVID-19 pandemic.

\begin{tabular}{ccccc}
\hline Academic/Research Activity & Decreased & Static & Increased & Total \\
\hline Bedside Teaching & $84(82.4 \%)$ & $18(17.6 \%)$ & $0(0.0 \%)$ & $102(100 \%)$ \\
Seminar Presentation & $73(71.6 \%)$ & $24(23.5 \%)$ & $5(4.9 \%)$ & $102(100 \%)$ \\
Journal Presentation & $75(73.5 \%)$ & $24(23.5 \%)$ & $3(3.0 \%)$ & $102(100 \%)$ \\
Research Activity & $69(67.6 \%)$ & $27(26.5 \%)$ & $6(5.9 \%)$ & $102(100 \%)$ \\
\hline
\end{tabular}

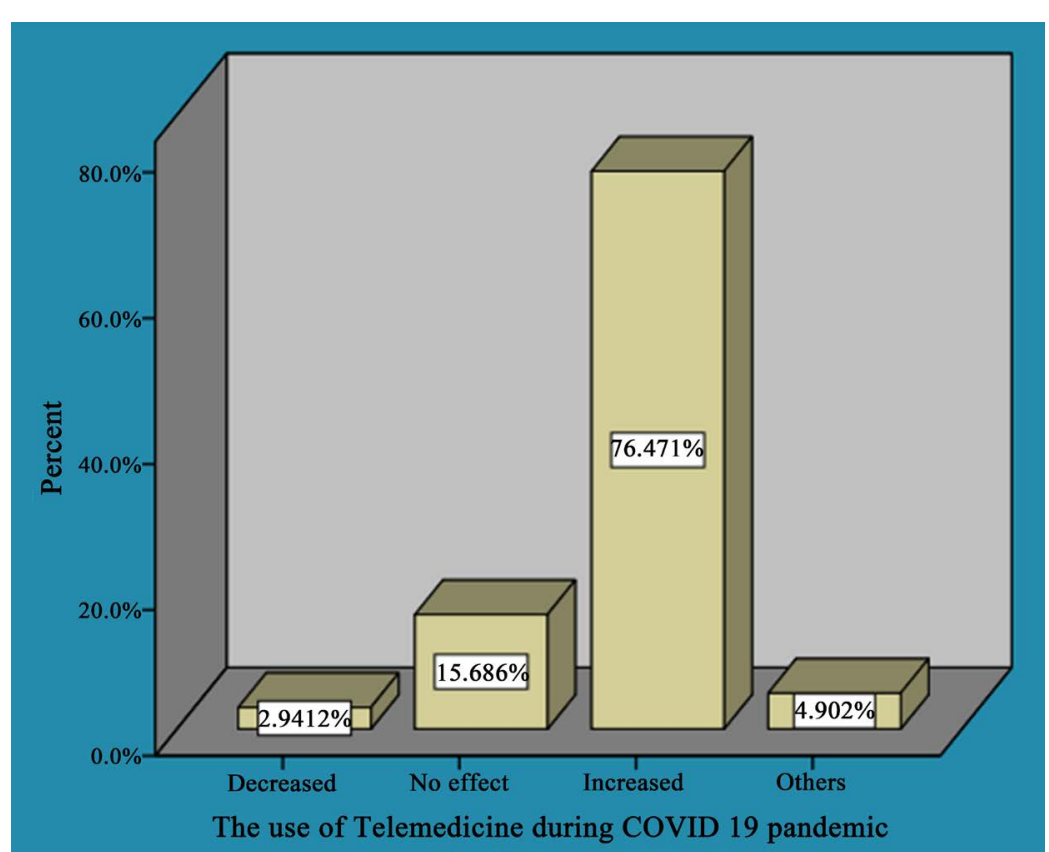

Figure 3. Use of telemedicine during COVID-19 pandemic. 


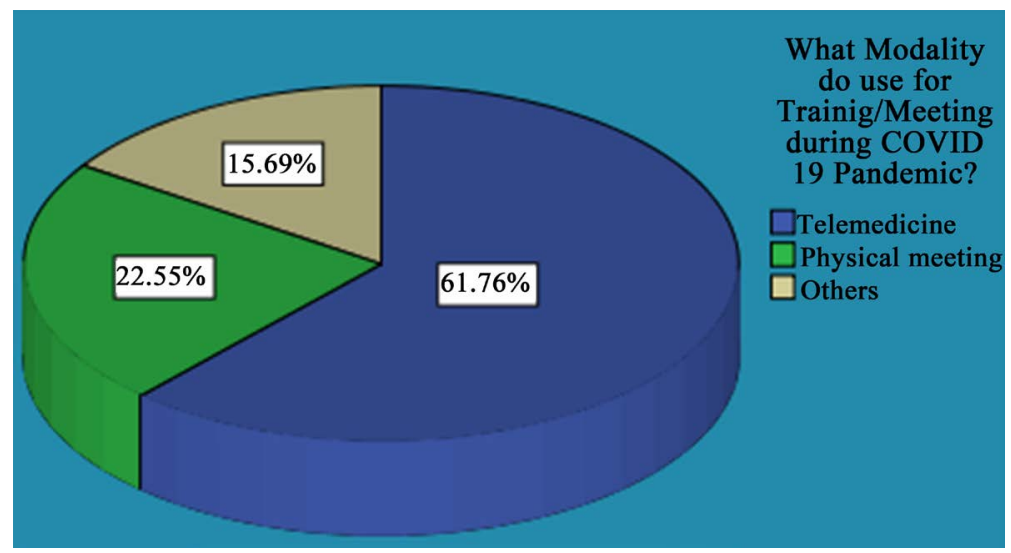

Figure 4. Modality adapted for training/meeting during COVID-19 pandemic.

need to be vigilant to protect ourselves. There is reliable information coming from the US indicating that otolaryngology is a high-risk group from COVID-19 infection. There is anecdotal evidence that a single endoscopic sinus case in China reportedly infected 14 people who were in the operating room. There is a presumed high risk in any procedures involving the airway. We advise to postpone all non-urgent surgery. Hospitals need to ensure ENT surgeons are supplied with the necessary PPE in order to avoid fatalities according to latest guidelines of the European Rhinological Society [5].

Otolaryngologist should wear fluid-resistant FFP3/FaceN95 mask for patients requiring urgent surgery or ENT consultation; Disposable hand gloves and gowns disposable and resistant to fluids, glasses or full face shield and surgeons are advised to double-glove during surgery [6]. A number of operating room personnel during urgent ENT surgery should be kept to a minimum [7]. The outcome from our study shows that $61.8 \%$ and $60.8 \%$ of ENT surgeons used N95 mask and eye goggles during consultation respectively.

Among Disposable, air purifying half-face piece respirators (DFHFRs), National Institute for Occupational Safety and Health, (NIOSH) approved N95 filtering face piece respirators or higher are recommended against airborne infectious diseases such as Ebola [8] [9]. Ninety groups (N95, N99, N100, P95, P99, P100, R95, R99, and R100) of FRP are listed by the U.S. National Institute for Occupational Health and Safety (NIOSH) [9].

$\mathrm{N}$ (not oil-resistant) means that respirators cannot be used in an oil droplet environment; R (slightly oil-resistant) and P (strongly oil-resistant) mean that this respirator can be used to protect against non-oily and oily aerosols. Numeric designations 95,99 and 100 indicate the minimum efficacy of the filter with $95 \%$, 99\%, and $99.97 \%$.

FFRs are classified into three groups by European Standard (EN 149:2001): FFP1, FFP2 and FFP3 with corresponding minimum filtration efficiencies of $80 \%, 94 \%$ and $99 \%$. Hence, FFP2 respirators are approximately equivalent to N95 FFRs, making them recommended for use in the US and some other countries to prevent airborne infectious diseases. However, since FFP3 respirators 
provide the highest level of protection, they are the only FFP class appropriate to the Health and Safety Executive (HSE) for healthcare settings security against infectious aerosols [10].

As a result, Safety Measures (SMs) have been relegated to protection against infection only through fluid repulsion. The particle protection provided by SMs $(0.04-1.3 \mu \mathrm{m})$ is $8-12$ times lower than that provided by N95 FFRs [11], but both are found to be equivalent to protection against influenza infection when concentrations of infectious viruses are low [12]. SMs have been cleared for sale in the United States by the Food and Drug Administration, while in the United Kingdom they must first comply with the Medical Devices Directive (MMD 93/42/EEC) [13].

According to the WHO, the ABHR (Alcohol based hand rub) is an alcoholic preparation (fluid, gel or foam) for use in the hand to inactivate and/or temporarily suppress the growth of the microorganisms. Such products may contain one or more types of alcohol, other active ingredients with excipients and humectants [14]. There are also non-alcoholics which are less favored by health agencies to combat the COVID-19 [15], which includes the Centers for Disease Control and Prevention (CDCs) [16]. This is due to their less efficient and slower range compared to alcohol-based sanitary products [17]. Indeed, the most significant element in assessing the effectiveness of a hand sanitiser is alcoholic material [17].

Adequate precaution should be taken when performing Otorhinolaryngological examinations during ENT consultation. During this pandemic period, avoid performing elective testing and ensure that the test is completely required at the moment and should not be delayed. Consider using vasoconstrictors and topical anesthetics to minimize the risk of coughing or sneezing, which may produce aerosols and stay in position [15].

Besides strict airborne and contact precautions, PPE is a requirement against SARS-CoV-2 for health care personnel. [18] [19] Otolaryngologists should select suitable protective equipment, based respectively on medical operations. Routine investigation or simple examination, such as anterior rhinoscopy and oropharyngeal inspection, require specific safety, including surgical mask, respirator, goggles, gown and gloves, NIOSH-certified disposable N95 [9].

When the procedures are likely to have close contact with respiratory droplets or aerosols triggered by excessive coughing, sneezing and deep breathing, such as throat swabs, nose and laryngeal endoscopy, epistaxis treatment and with foreign body in the pharynx, including wearing covers inside the gown, water-resistant boot covers, face shield in the event of a tearing accident, double-layer gloves are recommended, while the inner layer can provide greater security while offsetting the outer equipment. Invasive procedures on the airways such as tracheotomy are at the highest risk and require powered air purifying respirator (PAPR) to provide smooth aerosol resistance. In addition negative pressure environment will be ideal to control the aerosol [20]. 
On one hand, it should be noted that most nosocomial infections do not occur with careful protection, but when protective equipment are being removed with the hands accidentally getting contaminated and touching the eyes, nose and mouth. On the other hand, unlike the infectious disease department, emergency medicine, intensive care medicine, otolaryngology has limited awareness and experience about how to use PPE, thereby raising the risk of nosocomial infections during the process of doffing. Practical preparation and tests should be conducted prior to clinical use [21].

Considering the severity of virus transmission and the rapid increase in the number of infected patients, healthcare facilities should be charged to minimize patient accumulation in hospitals, reduce the risk of nosocomial transmission to staff and other patients, and ensure sufficient medical services and supplies to respond to respiratory infectious disease outbreaks [20]. In the Chinese experience, ENT clinic, routine endoscopy and surgery were halted in the early outbreak, only cases of emergency were seen and operations carried out until the epidemic was well managed. Elderly medical health workers or those with comorbidities such as cardiovascular disease, renal diseases, asthma, diabetes and cancer, vulnerable to more serious infection and with worse prognosis were exempted from exposure to procedures with high-risk infection [18].

During the pandemic, telemedicine was implemented. A smartphone device helps patients to schedule appointments and have a text consultation with physicians. Following an initial examination, the doctor will determine if a presence consultation is needed and is permitted to visit the hospital. In the meantime, most postoperative patients will provide guidance for remote recovery [18].

\section{Recommendations}

Consequently, Otorhinolaryngology Society Of Nigeria (ORLSON) provided this advisory/guidelines for otolaryngologists in Nigeria to assist in the present situation in their restructuring and service provision.

All Otorhinolaryngological wards, outpatient clinics, and operating theaters have been designated as high-risk areas because of the potential exposure to viral particles in nasal, pharyngeal, and tracheal secretions, saliva and sputum, blood, and cautery smoke. Entry of patients and escorts into an outpatient clinic or ward requires that they be screened at a triage desk (by staff wearing protective attire) for symptoms of a lower respiratory tract infection and/or a history of contact with persons believed to have had SARS-CoV-2. Each person's body temperature is measured.

Health care workers must take adequate and reasonable steps to prevent infection and the spread of disease to coworkers and patients. After a ceremony of hand cleaning, workers must don protective eyewear, N95 masks, and gloves. In between patients, it is mandatory to change gloves and wash hands. Patients are visible in the wards and clinics while healthcare staff are in protective gear. Upon exiting a high-risk area, protective equipment is removed and destroyed in ac- 
cordance with Infection Control Committee rules.

Health care workers are at risk of getting infected whether or not they are in direct contact with patients with SARS-CoV-2. Patients are possible sources of infection, hence every patient should be considered as a suspect. SARS-CoV-2 infection can spread among persons who have few or no symptoms and are yet to be identified as having the disease. Health care professionals' outfits minimize the spread of infection to patients. Another layer of protection from patients with COVID-19 is by having a triage desk at the entrance to the outpatient clinic. Staff at the front desk are at risk, but offer a second line of defense for frontline workers.

The outbreak of SARS-CoV-2 has resulted in health care professionals and supporting staff working toward making its prevention, detection, and treatment a day-to-day priority. This has led to the modification of almost every aspect of patient care. SARS-CoV-2 infection can spread among persons who have few or no symptoms and are yet to be identified as having the disease. Health care professionals' outfits minimize the spread of infection to patients. Another layer of protection from patients with COVID-19 is by having a triage desk at the entrance to the outpatient clinic. Staff at the front desk are at risk, but offer a second line of defense for frontline workers.

In the 8 months following the outbreak, $16 \%$ of patients admitted with SARS were health care workers. The overall mortality from SARS-CoV-2 during this period was $5 \%$. The number of new cases of SARS-CoV-2 is decreasing at the time of writing, and it is hoped that the provision Ototorhinolaryngological services gradually return to normal.

In future planning of Otorhinolaryngological services in Nigerian hospitals, services will be designed specifically to minimize the risk of cross-infections within the hospital setting. This may involve reducing the number of patients in wards to prevent crowding and reducing the number of appointments in clinics. The current infection control measures in the hospital and the triage system for outpatients are likely to remain in place because they have been effective. Infection of health care workers by patients with SARS-CoV-2 has been due to lapses in the use of personal protective equipment rather than to the equipment itself. Protected treatment areas in the Otorhinolaryngological wards and for outpatients, such as dedicated nasopharyngoscopy rooms, are planned.

\section{Conclusions}

Otolaryngologist is at high risk of being infected with SARS-CoV as they cope with upper respiratory tract during diagnosis, clinical review, sampling and surgery. ENT specialist is one of the most frequently consulted COVID-19 patients. During the COVID-19 pandemic, any patient with cough, sore throat, dyspnea, hyposmia/anosmia and a history of COVID-19 verified travel to the area should be considered potential COVID-19.

Otolaryngologists should wear FFP3/N95 fluid-resistant masks, removable 
and fluid-resistant gloves and gowns, glasses or full face shield when treating such individuals. We suggest that during the COVID-19 pandemic, chest CT should be performed in patients before major ENT surgery. It could be of great value in RT-PCR-negative individuals.

\section{Authors Contribution}

Shofoluwe Nurudeen Adebola conceived and designed the data, Lawal Jamila designed the online questionnaire and results, Kirfi Abdullahi Musa proof read the manuscript, Bello Muhammed Fufore analysed and wrote the result section, Afolabi Olusola Abdurrahman, proof read and discussed the manuscript

\section{Conflicts of Interest}

The authors declare no conflicts of interest regarding the publication of this paper.

\section{References}

[1] Zhou, P., Yang, X.L., Wang, X.G., et al. (2020) A Pneumonia Outbreak Associated with a New Coronavirus of Probable Bat Origin. Nature, 579, 270-273. https://doi.org/10.1038/s41586-020-2012-7

[2] Coronavirus Resource Center (2020) Johns Hopkins University \& Medicine. https://coronavirus.jhu.edu

[3] Gorbalenya, A.E., Baker, S.C., Baric, R.S., et al. (2020) Severe Acute Respiratory Syndrome-Related Coronavirus: The Species and Its Viruses-A Statement of the Coronavirus Study Group. https://doi.org/10.1101/2020.02.07.937862

[4] Chan, Y., Wong, W. and Lam, W. (2020) Practical Aspects of Otolaryngologic Clinical Services during the 2019 Novel Coronavirus Epidemic. An Experience in Hong Kong. JAMA Otolaryngology—Head \& Neck Surgery, 146, 519-520. https://doi.org/10.1001/jamaoto.2020.0488

[5] European Rhinologic Society (2020). https://www.europeanrhinologicsociety.org

[6] GOV.UK (2020) COVID-19: Infection Prevention and Control. https://www.gov.uk/government/publications/wuhannovel-coronavirusinfectionpre ventionandcontrol

[7] Han, D.-H., Willeke, K. and Colton, C.E. (1997) Quantitative Fit Testing Techniques and Regulations for Tight-Fitting Respirators: Current Methods Measuring Aerosol or Air Leakage, and New Developments. American Industrial Hygiene Association Journal, 58, 219-228. https://doi.org/10.1080/15428119791012874

[8] National Institute for Occupational Safety and Hygiene (NIOSH) (1996) NIOSH Guide to the Selection and Use of Particulate Respirators Certified under 42 CFR 84. National Institute for Occupational Safety and Hygiene (NIOSH), Cincinnati, DHHS (NIOSH) Publication No. 96-101.

[9] Centers for Disease Control and Prevention (CDC) (2015) Guidance on Personal Protective Equipment (PPE) to Be Used by Healthcare Workers during Management of Patients with Confirmed Ebola or Persons under Investigation (PUIs) for Ebola Who Are Clinically Unstable or Have Bleeding, Vomiting, or Diarrhea in U.S. Hospitals, Including Procedures for Donning and Doffing PPE. Centers for Disease Control and Prevention, U.S. Department of Health and Human Services, Atlanta. http://www.cdc.gov/vhf/ebola/healthcare-us/ppe/guidance.html 
[10] Lee, S.-A., Grinshpun, S.A. and Reponen, T. (2008) Respiratory Performance Offered by $\mathrm{N} 95$ Respirators and Surgical Masks: Human Subject Evaluation with $\mathrm{NaCl}$ Aerosol Representing Bacterial and Viral Particle Size Range. Annals of Occupational Hygiene, 52, 177-185. https://doi.org/10.1093/annhyg/men005

[11] Loeb, M., Dafoe, N., Mahony, J., et al. (2009) Surgical Mask vs N95 Respirator for Preventing Influenza among Health Care Workers: A Randomized Trial. The Journal of the American Medical Association, 302, 1865-1871.

https://doi.org/10.1001/jama.2009.1466

[12] Medicines and Healthcare Products Regulatory Agency (2010) Medical Devices Directive. Medicines and Healthcare Products Regulatory Agency, London.

[13] UK Government (2002) Statutory Instrument. Personal Protective Equipment Regulations. HMSO, London, 1144.

[14] Kampf, G. and Kramer, A. (2004) Epidemiologic Background of Hand Hygiene and Evaluation of the Most Important Agents for Scrubs and Rubs. Clinical Microbiology Reviews, 17, 863-893. https://doi.org/10.1128/CMR.17.4.863-893.2004

[15] CDC (2019) Show Me the Science-When \& How to Use Hand Sanitizer in Community Settings [WWW Document].

https://www.cdc.gov/handwashing/show-me-the-science-hand-sanitizer.html

[16] Ministério da Saúde (2013) RESOLUC, ÃO-RDC N॰6, DE10-DE MARC, O DE [Internet]. http://bvsms.saude.gov.br/bvs/saudelegis/anvisa/2013/rdc000610032013.html

[17] Zou, L., Ruan, F., Huang, M., Liang, L., Huang, H., Hong, Z., et al. (2020) SARS-CoV-2 Viral Load in Upper Respiratory Specimens of Infected Patients. The New England Journal of Medicine, 382, 1177-1179. https://doi.org/10.1056/NEJMc2001737

[18] Chang, D., Xu, H., Rebaza, A., Sharma, L. and Dela Cruz, C.S. (2020) Protecting Health-Care Workers from Subclinical Coronavirus Infection. The Lancet Respiratory Medicine, 8, e13. https://doi.org/10.1016/S2213-2600(20)30066-7

[19] Megan, L.R., Valerie, G. and Ashish, K.J. (2020) Critical Supply Shortages-The Need for Ventilators and Personal Protective Equipment during the Covid-19 Pandemic. The New England Journal of Medicine, 382, e41.

[20] World Health Organization (2020) Infection Prevention and Control of Epidemicand Pandemic-Prone Acute Respiratory Infections in Health Care: WHO Guidelines. http://apps.who.int/iris/10665/112656

[21] Centers for Disease Control and Prevention (2020) Interim Infection Prevention and Control Recommendations for Patients with Known or Patients under Investigation for 2019 Novel Coronavirus (2019-nCoV) in a Healthcare Setting. https://www.cdc.gov/coronavirus/2019-nCoV/hcp/infection-control.html 